\title{
1. Research on organizational innovation
}

\subsection{INTRODUCTION}

Innovations in products, services, practices, production processes, work structures and management systems are regarded as major factors in the formation of new businesses, growth of existing businesses, employment and level of income, organizational competitiveness and performance, and eventually higher standard of living and quality of life. In view of its role in the economic and social progress, innovation has a positive connotation among business leaders, policymakers, and scholars. The scope of research on organizational innovation is wide. Innovation is studied in several branches of social sciences including economics, management, psychology, and sociology. The number of academic publications in each field of study is continually increasing. To illustrate, Figure 1.1 shows the periodic growth of the scholarly articles published in management journals with the word 'innovation' in the title from 1960 to 2019.

Number of articles

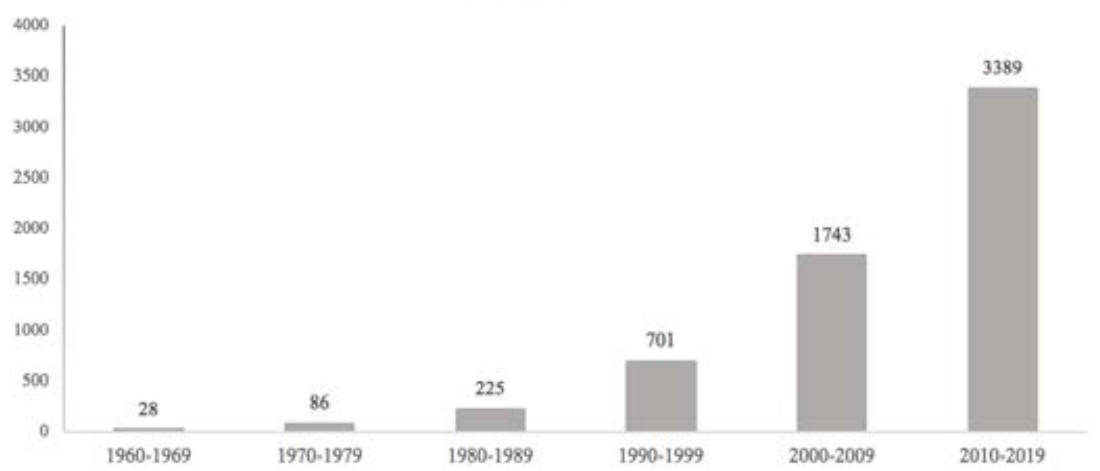

Figure 1.1 Number of articles with the word 'innovation' in the title in SSCI management journals from 1960 to 2019 
The size of research publications on innovation in the extant fields of study makes its understanding beyond reach of even seasoned scholars. To a new student of innovation, it might look intimidating and possibly discouraging. Yet, there are multiple peculiarities in the innovation literature, whose recognition and organization could help reduce the density of its size, and lure new enquiry. First, whereas multidisciplinary innovation research is desired, and is rightly encouraged, differences in innovation purpose, scope, definition, and measurement make its studies from different disciplines only superficially similar. Cross-disciplinary interpretations enrich explanations, but consistent evidence from the integration of cross-disciplinary studies of the causes and effects of innovation is hard to corroborate. Second, the term 'innovation' is used as an umbrella construct to represent related, overlapping constructs such as 'change,' 'creativity,' 'invention,' 'technology,' and 'technological change.' Each term has a large literature, multiple theories, and analytical preferences. Umbrella constructs also lack broad theoretical consensus from the fields of study they represent, and are exceedingly susceptible to validity challenges (Hirsch and Levin, 1999). Third, innovation is probed at different levels of analysis including the level of innovation (new program, product, practice), person (customer, user, primary adopter, secondary adopter), group (project team, inter-functional team), unit (function, business), organization (company, firm, business group), industry (market, sector, organizational population), and economy (nation, region, globe). Whereas multi- and cross-level studies of innovation are desired as they can help build more cogent explanations of organizational mechanisms for innovation, they are rare as each level of study has its own theoretical and empirical bent.

The voluminous literature is a constant feature of innovation research, but the complexity that emanates from overlapping concepts, disciplinary diversity, and ad hoc interpretation of research findings is overbearing. This book undertakes that the understanding of innovation in organizations could be facilitated by paying due attention to disciplinary differences in theorizing innovation and avoiding loose interpretation of research results. We draw insights from organizational economics, psychology, and sociology to help grasp the boundaries of innovation in its disciplinary fields; however, the disciplinary home of this book is business and management, the focus is on innovation at the level of organization, and the intention is to ease understanding of organizational innovation to enhance developing evidence-based theories.

The study of innovation at the level of organization is alternatively referred to as 'management of innovation,' 'innovation in organizations' and 'organizational innovation.' We use these terms interchangeably throughout the book. The word 'innovation' here refers to all types of innovation organizations may undertake, whether technology-based or not. We assume innovation is a means to organizational conduct and outcome, whether the outcome or performance 
is economic or non-economic performance. The word 'management' is understood here to embody different types of organization, whether business or non-business, manufacturing or service, private or public. The 'management of innovation' includes both generation (creation, development) and adoption (application, implementation) of innovation (technical, non-technical) in organizations. The term 'organizational innovation' is understood in two ways. In a more specific way, as in the economic-oriented studies of innovation in organizations, it represents nontechnological process innovations, typically in for-profit firms, in the manufacturing sector. In a broader way, organizational innovation refers to all types of innovation, whether technical or non-technical, in for-profit or non-profit organizations, in goods or services. We interpret the term broadly rather than narrowly. We also use the terms technical and technological interchangeably.

Studies of organizational innovation examine the external and internal conditions that induce organizations to engage in generating or adopting innovations, as well as estimating and assessing the impact of innovation on organizational conduct and performance. In the following chapters, these studies will be chronicled and explained to carve out key facets and dimensions of organizational innovation, coalesce its elements, and combine insights from existing research to inform and help guide future research. Despite many studies, interesting research questions of importance to managers and scholars regarding internal and external sources of innovation and effects of innovation on organizational outcomes remain unanswered. In the following chapters, we identify those questions that were answered and suggest ways to investigate those that were not.

The intention of this volume is to help readers navigate research on the management of innovation in organizations, provide them with information and knowledge for understanding the state of research in this field, and facilitate conducting new studies to advance the field. In accordance with Kuhn (1962), the book aspires to the development of an agreed-upon paradigm of gathering evidence, which requires both conceptual and methodological regularity. Theoretical frameworks will be offered to guide research in developing new models and theories to augment existing knowledge and help develop more persistent understandings of organizational innovation. Empirical results will be integrated to identify research gaps and provide a conceptual and methodological profile of the organizational innovation literature. A more general intention is to serve as an information source for students of innovation management and scholars new to this field of study, introducing them to terminology, theoretical perspectives, empirical findings, and connections between theory and empirics. To this goal, academic terms have been defined clearly, compared and distinguished from overlapping terms, and references are provided for those that would like to further explore specific features and 
characteristics of organizational innovation. While the language is academic, the writing is accessible.

In the following section, we first introduce the nature of innovation and offer definitions of organizational innovation from economic and social perspectives. This is followed by a brief overview of theories of organizational innovation, introducing the 'competition-wealth' and 'adaptation-progression' approaches to study innovation in organizations. The section after covers elements of innovation: type of innovation; innovation radicalness; process of innovation; and innovation openness. We then discuss sources of organizational innovation in four categories-environmental, organizational, individual, and innovation attribute. Throughout the book, elements and sources will be juxtaposed to classify innovation studies, synthesize findings, and offer conceptual models to guide new evidenced-based studies. In the final section, the structure of the book and content of its chapters are presented.

\subsection{DEFINITION OF ORGANIZATIONAL INNOVATION}

\subsubsection{What is Innovation?}

Godin (2015a) chronicled the idea of innovation historically and traced its presentation from the Greeks and Romans to its modern understanding. He offers that the connotation of innovation shifted from negative (Ancient Greece), to positive in the fourth century (Latin word innovo), negative once more in the sixteenth century after the Reformation in England, and positive yet again in the twentieth century (Godin, 2015a). Innovation represents newness or novelty, and in different disciplines it has included related terms such as imagination, originality, discovery, creativity, change, imitation and invention (Godin, 2008). The modern presentation of innovation can be traced to views expressed by Gabriel Tarde (1903 [1890]), a French sociologist, and Joseph Schumpeter (1983 [1911, 1934]), an Austrian economist, based on their understanding of innovation as an instrument of social and economic progress.

On the one hand, Schumpeter's view of innovation concerns the development and launch of new technology-based (or technological) products and processes by entrepreneurs and established organizations, where the newness is gauged at the level of product class or market. Innovation is defined as novel outputs, whether new goods or new quality of goods, new sources of supply or new markets (Schumpeter, 1983). Schumpeter's view of innovation is rooted in the context of economic development and technological change, and is centered on technical invention and its application to commercial entities (Damanpour, 2010). It occurs either through the act of entrepreneurial start-ups, which create new industries or produce major changes in the existing industries, or through 
the act of incumbent firms that boost efficiency and effectiveness of production systems to produce economic wealth. The currency of Schumpeterian innovation increased throughout the twentieth century, and was eventually adopted by the majority of policymakers and scholars in economics, business and management. The view of innovation as a technology-based, commercial phenomenon is referred to here as the economic (or economic-based) view of innovation.

On the other hand, Tarde presented a different view of innovation with an emphasis on imitation rather than invention, social change rather than technological change, and social progress rather than economic growth. Invention drives change, but society progresses by imitation. Tarde's views on imitation were followed in the twentieth century in the literature on the diffusion of innovation (Rogers, 2003 [1962, 1983, 1995]). Studies of the diffusion of innovation posit that scientific discovery drives invention, which in turn initiates innovation in new products and practices that are disseminated in a social system and are adopted by the members of that system. The first or early application or use of a new product or practice is regarded as innovation from the perspective of the adopter. Hence, Rogers' definition of innovation as an object or practice that is perceived as new by the unit of adoption. This understanding of innovation is referred to here as the social (structural-, behavioral-based) view of innovation.

The economic and social views together convey that the purpose of innovation is to provide economic benefits to generators and adopters and lead to social change and advancement. They capture the essence of innovation as a construct that can represent both the generation of a product or practice new to a market, social system, or an organizational population, as well as the adoption of an existing product or practice new to the adopting person, unit, or organization. In this regard, the innovator is not only an entity that creates and launches a new technology, product, or practice, but also the entity that pioneers in choosing and using that technology, product, or practice. Both entities expect innovation to contribute to their conduct and outcomes, whether the nature of innovation is technological or nontechnological and the nature of contribution is commercial or non-commercial.

\subsubsection{What is Organizational Innovation?}

From a Schumpeterian perspective, innovation is a function of entrepreneurship, where the entrepreneur creates wealth by producing new resources or enhancing the potentials of existing resources. Accordingly, Drucker (1985) defines innovation in organizations as an activity that creates purposeful, focused change in the organization's economic or social potential. This general definition of innovation can apply to all types of organization - start-ups, small 
and well-established - but it does not specify the defining features of innovation in organizations, including the process and typologies of innovation. A more detail, encompassing definition is offered by Crossan and Apaydin (2010, p. 1155):

Innovation is: production or adoption, assimilation, and exploitation of a value-added novelty in economic and social spheres; renewal and enlargement of products, services, and markets; development of new methods of production; and establishment of new management systems.

This definition illustrates the province of research on organizational innovation.

First, innovation in organizations is studied as both outcome and process. Innovation outcome and innovation process research are denoted as studies of innovativeness and innovating, respectively (Van de Ven and Rogers, 1988). Research on innovation as outcome aims to identify the contextual and organizational conditions that determine organizational innovativeness. The studies of innovativeness are referred to as variance studies, and are primarily large-sample studies of the influence of one or more set of determinants on one or more innovations generated or adopted by organizations (Gopalakrishnan and Damanpour, 1997). Research on innovation as process aims to identify how organizations go through the process of generating (developing, producing, and distributing) or adopting (selecting, implementing, and monitoring) innovations. The studies of innovating are mainly case studies of one or few innovations in organizations (Van de Ven, Angle, and Poole, 1989; Wolfe, 1994).

\subsubsection{Research on Organizational Innovation}

The studies of innovativeness in organizations has been influenced by theoretical trends, empirical conditions, and innovation attributes. First, the size of studies of innovativeness exceeds those of innovating. The small size of innovating studies is partly because research on the process of innovation requires longitudinal data, which are scarce, and partly because researchers can examine one or few innovations only, constraining generalization. The large size of innovativeness studies is because they often investigate innovation as outcome, and are cross-sectional despite the recognition of path dependency of innovations. These studies generally perceive that innovation produces positive outcomes for generating or adopting organizations, a phenomenon Rogers (2003) referred to as 'pro-innovation bias.' This bias induces policymakers and organizational leaders to take risks of unintended, unexpected, and undesired outcomes and allocate resources to innovation. 
Second, different theoretical perspectives have governed research on organizational innovation. This research was pioneered in the United States in the 1960s, primarily in organizational sociology (Evan, 1966; Hage and Aiken, 1967; Rogers, 2003 [1962, 1983, 1995]; Thompson, 1965). In the 1970s and 1980 s, the locus of this line of research moved to organization management in tandem with the growth of business schools in the United States and their gradual transition from business education to research institutions. In business schools, research on organizational innovation has been housed usually in management departments, where research activities have evolved along the trajectory of management theories that have gained currency over time. Examples are behavioral theories, structural contingency theory, strategic organization design, population ecology, organizational economics, institutional theory, resource dependence theory, resource-based view, and dynamic capability (Barney and Ouchi, 1986; Burgelman, 1983; Burns and Stalker, 1961; Christensen, 1997; Cyert and March, 1963; Donaldson, 1995; Drucker, 1985; Hage and Aiken, 1970; Katz and Kahn, 1966; Mintzberg, 1979; Pfeffer and Salancik, 1978; Scott, 1997 [1992]; Teece et al., 1997; Tushman and Anderson, 2004; Van de Ven, Angle, and Poole, 1989). These theories associate with one or more subfields of management such as organizational behavior, organization theory, strategic management, and entrepreneurship. Innovation studies are thus multi-perspective and are conducted by scholars with specific theoretical orientation.

Third, in addition to being multi-perspective, innovation is a multistage (development, commercialization, adoption, implementation) construct and is studied at various levels of analysis (individual, group, unit, organization) (Sears and Baba, 2011). Hence, its definition varies to accommodate a study's level of analysis and the stage of innovation process. Considering the level of analysis, for instance, when the subject of interest is an individual employee of an organization, innovation is defined as an idea pertaining to an object or practice perceived new to the employee, and innovative behavior is defined as the application of new ideas, products, processes, and procedures to the employee's work role, work unit, or organization (Rogers, 2003; West and Farr, 1990; Yuan and Woodman, 2010). When organization is of interest, innovation is defined to reflect the generation or adoption of innovation by organizations in a population. Considering the stages of innovation process, innovation is defined as the process of developing, producing, implementing, and using a new practice, process, product, or service (Thompson, 1965; Tornatzky and Fleischer, 1990). Similar differences and peculiarities in the definition of innovation exist for features of innovation such as type (product, service, process, technical, managerial), magnitude (radical, incremental, discontinuous, exploitative), newness (new vs. improved, first time vs. early use), and so on. 
Fourth, innovation is a practical construct; it is a means to an end, and is introduced to make a positive change. The positive connotation of innovation suggests that organizations generate and adopt innovations across their value chain with the expectation that they fulfill their strategic intent, make operations more efficient and effective, improve quality of products or processes, and contribute to organizational performance. The desired outcome, whether productivity, competitiveness, quality or efficiency, has been built into many definitions of innovation, making studies of performance consequences of innovation a popular research track. However, innovation consequence research cannot be easily reconciled with innovation antecedent research because few studies have explored the entire chain (antecedent $\rightarrow$ innovation $\rightarrow$ consequence).

The multiplicity of research domains and diversity of conceptualization of innovation have resulted in numerous differences in the empirical studies of innovation, thus exacerbating understanding. More macro differences, especially those from a variety of theoretical perspectives and circumstances, cannot be bridged. More micro differences, especially those from organizational diversity, and some from disciplinary diversity, are partially explainable when the studies are properly positioned (details in Chapters 7-9). This is important because our ability to learn from the rich body of this literature and enhance our knowledge base requires some degree of generalization, without which this line of research cannot be advanced by future endeavors.

\subsection{THEORETICAL PERSPECTIVES}

\subsubsection{Theories of Organizational Innovation}

Studies of organizational innovation are grounded on behavioral-based, economics-based, and structural-based perspectives. For instance, from an economics-based perspective, Fagerberg et al. (2012b) defined innovation studies as the scholarly study of how innovation takes place, what explanatory factors are, and what economic or social consequences innovation has. They identified three research strands: economics of R\&D, organizing innovation, and innovation systems. From a structural- and behavioral-based perspective, Lam (2005) classified theories of organizational innovation into three streams: (1) organizational design theories, including contingency theory and industrial economics; (2) theories of organizational cognition and learning; and (3) theories of organizational change and adaptation, including evolutionary change, organizational transformation and renewal, and strategic adaptation. Via a systematic review of peer-reviewed journals in social sciences from 1978-2008, Crossan and Apaydin (2010) identified a mix of behavioral-, economics-, and structural-based perspectives, including institutional, economics and 
evolution, network, resource-based view, dynamics capability, knowledge and learning, and adaptation and change as key theoretical perspectives in the studies of innovations in organizations. These theoretical perspectives offer myriad explanations on why, what, and how organizations engage in innovation activities. The multiplicity and fragmentation of theoretical explanations coupled with the complexity of the concept prevent a coherent framework to guide research (Lam, 2005).

Yet, for organizational leaders, innovation is a practical construct to serve strategic intent. On the one hand, the intent is to enable the organization to compete in the marketplace, generate superior performance, and create wealth for owners. On the other hand, the intent is to adapt to environmental change, operate efficiently and effectively, and stay in business. The first intent associates with the generation of products and practices new to a market or an industry. The second intent associates with the adoption of product and practices new to the organization. These strategic intents are not mutually exclusive, nor are they competing. An organization may pursue both, consecutively or simultaneously contingent on its external circumstances and internal preferences. We offer two general approaches associated with these strategic intents to help make sense of the existing studies and develop models and frameworks for launching new studies.

\subsubsection{Competition-wealth and Adaptation-progression}

The competition-wealth and adaptation-progression approaches are to facilitate understanding of antecedents, processes, and consequences of innovations in organizations (Damanpour, 2017). Studies from the competition-wealth approach are grounded in the economic-based theories of innovation. They view the organization primarily as an economic entity, competing in one or a few markets, and consider innovation mainly as a means to oust or outperform rival firms in the market (Fagerberg, 2005; Sundbo, 2001; Schilling, 2013). The studies from this perspective have often focused on the generation of new technology-based, commercial products and processes in manufacturing organizations. Innovation is a means to improve organizational efficiency and productivity, increase market share and profitability, and generate economic wealth for owners. In organization management, competition-wealth is prominent in business policy and strategy, global (international) business, and technological and strategic entrepreneurship (Evangelista and Vezzani, 2010; Hitt et al., 2001a; Lengnick-Hall, 1992; Teece et al., 1997).

Studies aligned with the adaptation-progression approach are grounded in social-based theories where the organization is viewed as a social entity to produce objects and solutions that society needs, while procuring reasonable returns (Abrahamson, 1996; Ansari et al., 2014; Sundbo, 2001), and 
innovation is a means of adaptation to the external environment, assisting the organization to operate well and progress. This view accords with the behavioral theories of innovation that stress social relationships to channel people's activities to promote creation of new ideas, facilitate the implementation of those ideas, and devise mechanisms to enhance the innovation-decision process. In the fields of management, the adaptation-progression approach is prominent among scholars in organization design and theory, human resource management, and organizational behavior (Damanpour and Schneider, 2006; Hage and Aiken, 1970; Ross, 1974; Van de Ven et al., 1989). Studies from this perspective involve technical or nontechnical innovations in business and public organizations.

The competition-wealth and adaptation-progression perspectives are similar in several ways. Both consider the organization as a vehicle for innovation and recognize innovation as a means to organizational performance and effectiveness. Both approaches subscribe to organizations as open systems, a perspective in organization studies that emerged in the second half of the twentieth century by the application of system theory to organization management (Ackoff and Emery, 1972; Churchman, 1968; von Bertalanfy, 1951, 1968). An organization is defined as an open system that is composed of interdependent parts (subsystems) and is embedded in an environment with which it interacts and exchanges material, information, and energy (Ackoff, 1981; Emery and Trist, 1960; Katz and Khan, 1966; Scott, 1997 [1992]). The environment is also a system, albeit a larger and more complex system than the organization, with its own subsystems and environment. Two layers of the environment surround the organization: the operating environment and the general environment. Changes in either prompt changes in the organization to maintain the organization-environment equilibrium. Organizations may also choose to pre-empt changes in the operating environment by introducing state-of-the-art technologies and groundbreaking innovations. In this vein, from the open system perspective, innovation is considered as a means of coping with the environment, and possibly changing it.

However, the competition-wealth and adaptation-progression approaches differ regarding the chain of desired outcomes from innovation and the mechanisms through which those outcomes can be attained. The competition-wealth studies adhere to the paradigm of industrial innovation, view organizations as mainly an economic system, rely on the generation of innovation, give precedence to technological capability, and focus on the development of new products and services to boost innovation outcome and firm performance, often profitability. Like organizational economics, these studies treat an organization as a black box and do not delve into details of internal processes and managerial mechanisms. The adaptation-progression studies, on the other hand, view an organization mainly as a social system, one that concerns the 
adoption of innovation, gives precedence to innovation capability, and assume organizational performance depends on compositions of innovations of different types rather than merely new technology-based products (Damanpour, Walker, and Avellaneda, 2009; Roberts and Amit, 2003).

As organizations are both economic and social entities and can both generate and adopt innovations, the two approaches are co-dependent. Yet current studies subscribe to one without regard to the other. Bridging this fragmentation provides a fuller explanation of the process of innovation in organizations, helping identify its drivers and consequences. Since each perspective only partly explains why and how organizations innovate, they are conjoined in this book to inform and enhance research on organizational innovation.

\subsection{ELEMENTS OF INNOVATION IN ORGANIZATIONS}

According to the scientific method, a complex whole (problem, phenomenon, system) can be explained by analysis and synthesis (Ackoff, 1962). Analysis refers to breaking the whole into its fundamental elements in order to understand the nature and behavior of each; synthesis refers to interactions between elements and the accumulation of their nature, behavior and interactions to explain the whole. We consider four primary elements of organizational innovation: types of innovation, innovation radicalness, innovation process, and innovation openness. Some authors clearly ascertain innovation elements in their study; others offer a general definition of innovation and leave the peculiarities of their study for the reader to decipher. The elements of innovation combined with its sources (causes, drivers, motivators) identify the parameters of a study, help understand the study's implications, assess its relevance, and integrate its findings with the other studies with similar features. Together these help the reader to better understand research results, avoid unrelated interpretation, and prevent erroneous application.

\subsubsection{Types of Innovation}

Multiple typologies of innovation have been advanced. Schumpeter (1934) considered innovation as 'new combinations' of existing resources and referred to five types of innovations: new products, new methods of production, new source of supply, new markets, and new ways of organizing business (Fagerberg, 2005). At the organizational level, an early example is the distinction between technical and administrative innovations (Evan, 1966). In a review of typologies of innovation, Zaltman et al. (1973) identified 20 types and grouped them under three categories: in terms of innovation focus, innovation effect, and organizational subsystem (task, political, and cogni- 
tive). Since Zaltman et al.'s review more innovation types have been introduced (e.g., architectural, business model, exploratory, exploitative, green, sustainable), and new conceptual and evidenced-based taxonomies have been developed (Damanpour, 2017). For example, Meeus and Edquist (2006) offer a two-dimensional taxonomy juxtaposing product innovations in goods and in services with technological and organizational process innovations. Tether and Tajar (2008) offer a three-dimensional taxonomy juxtaposing productprocess, technological-nontechnological, and intraorganizational-interorganizational cooperation.

The technical-nontechnical and product-process pairs have frequently been compared regarding the differences in antecedents and consequences. Research on product versus process innovations has been more widespread than between technical and nontechnical innovations. The OECD Oslo Manual (2005) added questions for nontechnical innovations (organizational and marketing). The EUROSTAT Community Innovation Survey (CIS) added those questions to the questions on product, service, and process innovation since CIS-4 (2002-2004). The biannual administration of CIS in the EU nations has provided data for comparison of technical and nontechnical innovations, boosting empirical studies of their relationships somewhat. Figure 1.2 illustrates the periodic growth of publications on four primary innovation types from 1960-2019.

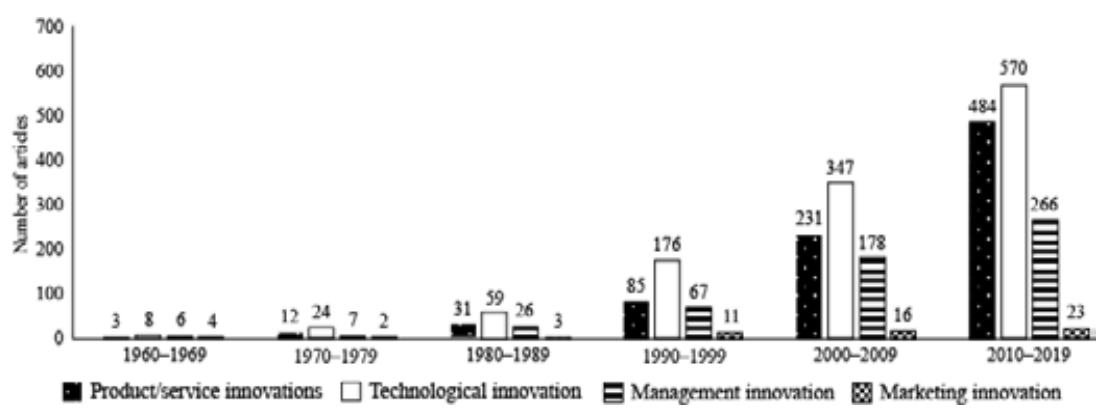

Figure 1.2 Number of articles with four types of innovations in the title in SSCI management journals from 1960 to 2019

\subsubsection{Innovation Radicalness}

Innovation radicalness is defined to signify three aspects of innovation: (1) originality or novelty; (2) departure or difference; and (3) outcome or impact. Regarding originality, radicalness is the extent to which the innovation advances the existing knowledge; regarding departure, it is the degree of 
departure from existing products, practices, or routines; and for impact, it is the extent to which innovation changes the adopter's behavior or performance (Damanpour, 2017; Knight, 1967; McDermott and O’Connor, 2002; Slater et al., 2014). Among these aspects, an innovation's radicalness has usually been conveyed by its newness. Newness is a relative term that can be implied and understood independently at various levels of innovation province. For instance, innovation can be new to an employee of the organization, but not to the organization itself; to an organization, but not to the organizational population it is a member of. The common standard to measure newness at the level of product class or industry is a patent. This measure of innovation is mainly used for the generation of technological innovations, where an innovation's originality, departure and impact coalesce for gaining competitive advantage at the level of industry or market.] For the adoption of technological or non-technological innovations, however, novelty and departure relate to the adopter rather than innovation, and outcome is gauged at the level of organization rather than market or industry.

Innovation radicalness is a continuum, but it is usually probed categorically. Often, two categories that signify high versus low levels of originality, departure, and impact have been examined. At the level of innovation or industry, terms such as sustaining versus disruptive, competence-enhancing versus competence-destroying, and continuous versus discontinuous are employed (Christensen, 1997; Schilling, 2013; Tushman and Anderson, 1986). At the organizational level, terms such as routine versus non-routine, variation versus reorientation, and exploitative versus exploratory are used (Jansen et al., 2006; Normann, 1971; Zaltman et al., 1973). Minor differences aside, these pairs can be subsumed under a more common, general term - radical versus increment innovation. Radical innovations are innovations that depart fundamentally from existing products and practices, and cause major changes in the internal activities and/or outcomes of the organizations. Incremental innovations are innovations that result in minor changes in the existing activities and outcomes (Dewar and Dutton, 1986; Ettlie, Bridges, and O'Keefe, 1984; McDermott and O’Connor, 2002; Schilling, 2013).

\subsubsection{Innovation Process}

The process of innovation has received research attention from both economic and social perspectives. From the economic perspective, using the 'research-development-commercialization' linkage, researchers have probed the process of development and commercialization of technological innovations. From the social perspective, relying on the 'invention-innovation -diffusion' linkage, researchers have studied the process of diffusion and adoption of innovations. 
The process models are usually conceptualized as sequential steps through which innovation is generated and adopted. The majority of these models assume that innovation is generated and adopted in the same organization. They delineate the innovation process as recognition of a problem or an opportunity, generation and formulation of ideas, development, commercialization, adoption, and implementation. Discontinuance or abandonment of innovation is barely noted. A minority of the process models distinguish between generation and adoption processes. For example, Tornatzky and Fleischer (1990) divided innovation process into processes of 'developing' and 'using'; Klein and Sorra (1996) distinguished between 'source-based' and 'user-based' processes; Greenhalgh et al. (2004) separated 'resource system' from 'user system'; and Gopalakrishnan and Damanpour (1997) distinguished between 'generation' process and 'adoption' process. Labels notwithstanding, the first process depicts how organizations research, develop, and commercialize a product or practice new to a market, product class, or industry; the second process depicts how organizations select, adapt, and use an existing product or practice for the first time. Throughout this book, we refer to these processes as generation and adoption of innovation, respectively.

This book assumes that the distinction between generation and adoption of innovation is essential in consolidating current studies, understanding similarities and differences of their findings, and developing evidenced-based theories of innovations in organizations. Whereas organizations can both generate and adopt innovations to achieve their goals, the generation and adoption are considered as distinct processes that usually occur at different parts of organization under different external and/or internal conditions, and are not necessarily affected by the same sets of determinates. In addition, we put forth that organizations may both generate and adopt innovation of different types whose necessity, function, and contributions differ in different types of organizations.

\subsubsection{Openness of Innovation Process}

Radicalness relates to innovation outcome, openness relates to innovation process. Chesbrough $(2003 \mathrm{a}, 2003 \mathrm{~b})$ introduced the concept of open innovation as an approach where the focal organization relaxes its tight control over the innovation process and involves partners through various means of interorganizational cooperation in one or more stages of the development of innovation. Chesbrough (2003a) argued that the flexibility in developing and commercializing internal and external ideas in cooperation with other firms expedites the development of new products and processes for the current markets and facilitates their launch into new markets. Innovation scholars embraced the concept of open innovation as it coincided with the continued advancement of information and communication technologies (ICT), globali- 
zation of business operations and services, and the demise of large in-house R\&D organizations (Damanpour, 2017). Research on open innovation grew rapidly, making it a primary concept in technology management and business strategy.

While Chesbrough (2003a) conceptualized open innovation for both inflow and outflow of information and knowledge in organizations, research on open innovation has mainly explored the inflow of knowledge. Relying on the concept of absorptive capacity (Cohen and Levinthal, 1990), studies of open innovation probe mainly the role of external knowledge for the generation of technological product innovations. More generally, however, innovation openness is defined here as the extent to which organizations involve external actors or entities in the process of generation or adoption of technological or nontechnological innovations in organizations (Damanpour, 2017). Openness concerns the locus of innovation, which can be internal to the firm versus distributed between firms through alliance, networks, and supply chain (Tether and Tajar, 2008). With continued advancement of communication speed, information spread, and interaction ease among people and organizations across the world, we expect openness to play an important role in developing and implementing any type of innovation in any type of organization.

Open innovation was introduced as an alternative to closed innovation, where the innovation is fully developed in-house (Chesbrough, 2003b). Since neither full openness nor full closeness of innovation are possible, we consider openness as a continuum, distinguishing less open (organic) from more open (nonorganic) innovations. Organic innovation pertains to the generation or adoption of a new product, process, service, or practice where innovation activities are mostly conducted in-house. Nonorganic innovation pertains to the generation or adoption of a new product, process, service, or practice where external actors and entities are significantly engaged in one or more stages of the innovation process. A distinction between organic and nonorganic innovations, similar to that between technological and nontechnological and radical and incremental innovations, can help to clarify the effects of internal and external knowledge sources on innovating and innovativeness in organizations.

The four elements of innovation discussed in this section are detailed in Chapters 3-6, where various features and aspects of each is described, extant research is presented, and conceptual models for future investigations are proposed. The four elements can be combined to construct two-by-two, two-by-three, or more complex conceptual models. Figure 1.3 shows a few examples of two-by-three models. 10 Such models are useful to organize research on organizational innovation, form evidenced-based profiles, and provide insight to guide future research. 

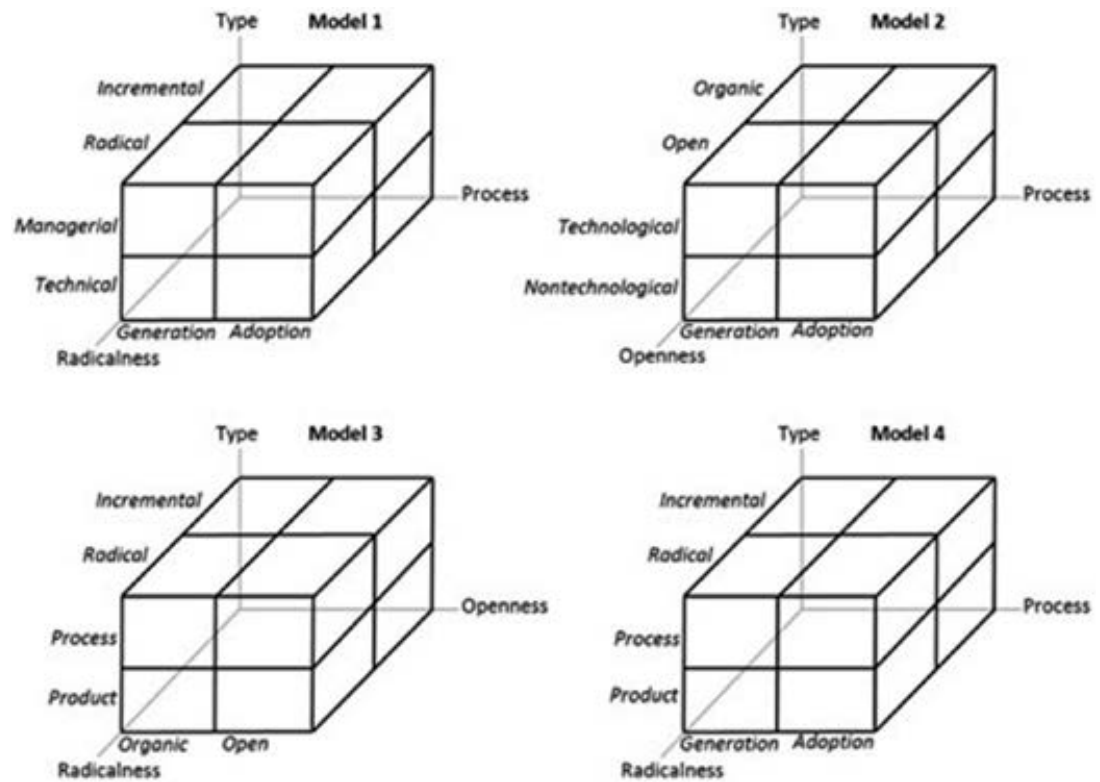

Figure 1.3 Illustrative models of combinations of innovation elements

\subsection{SOURCES OF ORGANIZATIONAL INNOVATION}

Business and public managers are keen to understand conditions under which their organization can successfully innovate. Academicians have responded by studying factors that influence innovations in organizations. Most empirical studies have examined innovation as a single construct, a minority include pairs of innovation type (technical, administrative) or radicalness (radical, incremental), and few involve pairs of innovation process (generation, adoption) or openness (organic, open). Sources or causes of organizational innovation are categorized into four groups: environmental-level factors, organizational-level factors, individual-level factors, and innovation-level factors (Baldrige and Burnham, 1975; Damanpour and Schneider, 2006; Kimberly and Evanikso, 1981; Storey et al., 2016; Vagnani and Volpe, 2017). Myriad factors from various disciplinary perspectives have been associated with each category. Environmental sources signify external and contextual characteristics that influence innovation, organizational sources reflect internal characteristics such as strategy, structure, and culture; individual sources signify the role of people (leaders, managers, employees); and innovation attributes signify real or perceived differences between innovations. 


\subsubsection{Environmental (External) Factors}

Environment consists of all entities outside of an organization's boundary, whose characteristics could influence the behavior of that organization (Figure 1.4). The external environment is classified in two parts. The one nearer to the organization including customers, suppliers, and competitors is variably termed operational, competitive, transactional, and micro environment; the one farther from the organization, including economic, social, political, cultural, and educational systems, is called the general or macro environment. The components of the general environment are demographic, technological, economical, legal, social, and political. The components of the operational environment vary by the type of industry, sector, or organization. Changes in the macro or operating environment trigger changes in organizations. Organizational change, in turn, can occur through the introduction of innovation. In this vein, environmental factors reflect the context of innovation, which may differ in pairs of organizational types, such as business versus public, high-tech versus low-tech, start-up versus incumbent, and manufacturing versus service.

Typical environmental factors in business organizations are market competition, industry structure, governmental regulation, technological intensity, supplier power and customer demand (Cohen and Levin, 1989; Roberts and Amit, 2003; Schilling, 2013). In public organizations, they are urbanization, deprivation, ethnicity, political orientation, and community affluence (Boyne, 2002; Ashworth et al., 2009; Walker, 2008). Černe et al. (2016) identified market orientation, dynamism, and competitiveness as typical external factors for nontechnological innovations in business organizations. For technological innovations in manufacturing organizations, Damanpour and Aravind (2006) identified competition, concertation, technological opportunity, appropriability conditions, and growth of demand as environmental factors. More generally, studies that include diverse organizational types have used a mix of these factors (Crossan and Apaydin, 2010).

\subsubsection{Organizational (Internal) Factors}

Whereas external situations and events trigger organizations to innovate and change, internal organizational conditions reflect their resolve and capacity to do so. Even in a placid environment, organizations may choose to strengthen their innovation capability in order to stay in business, gain competitive advantage, boost performance and grow. In this sense, engaging in innovation activity is a strategic choice. Innovation requires financial and human resources, enabling structure and processes, and a work climate and culture amenable to creation and implementation of new programs. 


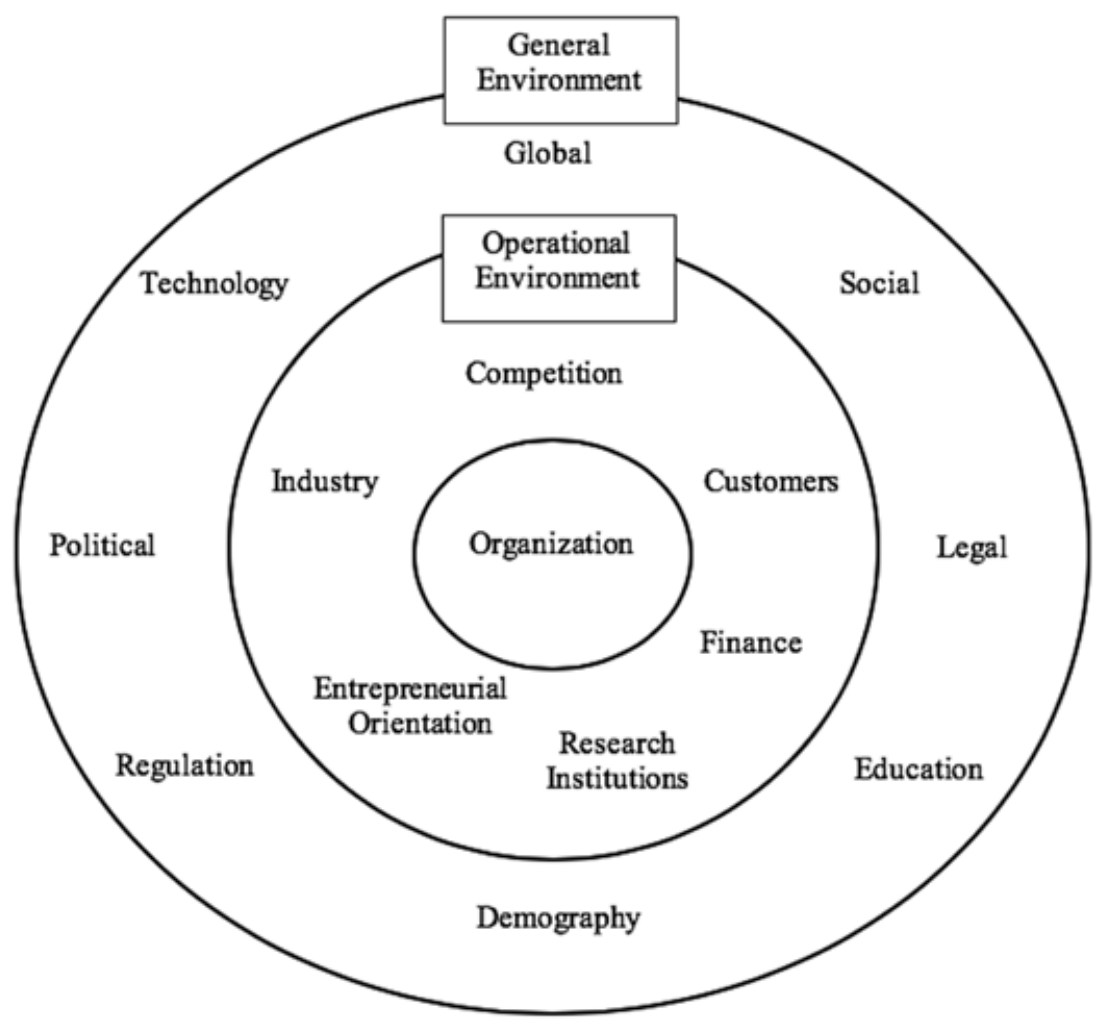

Figure 1.4 Primary components of general and operational environments

According to the strategic choice perspective, organizations choose their strategies in concurrence with environmental conditions in order to seize opportunities, avoid threats, and achieve performance goals (Child, 1977; Hambrick, 1983; Hrebiniak and Joyce, 1985). Porter (1980, 1985) advances that organizations choose from three generic, competitive strategies to outperform industry rivals: cost leadership, differentiation, and focus or niche. In innovation studies, the development of a new technology, product, or service unique to the industry is associated with the differentiation strategy. However, organizations also introduce other types of innovations along the value chain, including customer service innovations in marketing and sales and managerial innovations in human resources and procurement. 


\subsubsection{Individual (Leadership) Factors}

Managers and non-managers have roles to play for innovation. Organizational employees' roles involve the two ends of the innovation process: idea generation, and implementation. The managers' role, especially the role of top managers or strategic leaders, is more crucial and involves all stages of the innovation process. Top managers influence innovation because they direct the strategic processes of identifying threats and opportunities, formulating policy to create and control change, allocating resources to innovations activities, and developing culture and shaping capabilities to encourage and enable innovation (Bantel and Jackson, 1989; Elenkov et al., 2005; Hoffman and Hegarty, 1993). They are also responsible for managing the responsibilities and performance of middle and line managers, instituting values supportive of innovation, empowering change agents, creating urgency for innovation, and rewarding creative actions and entrepreneurial behavior (Damanpour and Schneider, 2006; West and Anderson, 1996; Yuan and Woodman, 2010).

Prior research has explored three sets of leadership characteristics on organizational innovations: demographic (age, gender, education, experience), personality (agreeableness, authoritarianism, openness to experience), and behavioral (inspirational motivation, championing innovation, contingent rewards) (Damanpour, 2017). Studies in both business and public context have identified transformational leadership, change-oriented behavior, favorable attitude and disposition toward change, and skills and competence to create a climate supportive of innovation as key leadership factors supportive of innovations in organizations (Crossan and Apaydin, 2010; de Vries et al., 2016; Ekvall and Arvonen, 1991; García-Morales et al., 2008a; Jantz, 2016). Research on organizational leadership generally supports these characteristics and endorses leadership of innovation as an important driver of creating and implementing new ideas (Mumford et al., 2002; Mumford and Licuanan, 2004).

\subsubsection{Innovation Attributes}

Innovation diffusion scholars underlined differences among innovations, and stated that innovations cannot be studied as equivalent units because of differences in their characteristics (Damanpour, 2017). Research on the innovation attribute-diffusion relationship was pioneered in rural sociology for individual adopters (Fliegel and Kivlin, 1966; Rogers and Shoemaker, 1971), and spilled over to organization studies for organizational adopters (for reviews see Zaltman et al., 1973; Wolfe, 1994). Many attributes of innovation have been identified. For instance, Zaltman et al. (1973) reported approximately 20 attributes. Wolfe (1994) defined 18 attributes and identified about the same 
number with similar definitions but different names. Tornatzky and Klein (1982) reviewed studies of the relationship between innovation attributes and innovation adoption and implementation, listed 30 attributes included in the original studies, and recognized ten as the most frequently studied attributes. However, Rogers (2003) observed that variance in the rate of adoption of innovation is explained primarily by five attributes: perceived relative advantage, compatibility, complexity, trialability, and observability. These five attributes are among those identified by Zaltman et al. (1973), Wolfe (1994), and are among Tornatzky and Klein's (1982) list of ten primary attributes. The other five attributes in Tornatzky and Klein's list of ten are: innovation cost, communicability, divisibility, profitability, and social approval.

While the studies of innovation attributes have concerned mainly the adoption of innovation in organizations, their influence on the generation of innovation is also pertinent. For example, would innovators and entrepreneurs involve or not involve in the development of a new product or practice because of their perception of relative advantage, complexity, profitability, or social approval of that product or practice? Also, while innovation attributes have been usually probed as predictors of the rate and speed of innovation adoption, their role as moderators of the relationship between organizational and managerial factors with innovation can reveal why some innovations are adopted or generated more readily in organizations. In Chapter 6 and 7 we elaborate on such questions, discuss the external and internal sources of innovations, and integrate research findings to present the current state of empirical studies of antecedent or determinates of organizational innovations.

Table 1.1 summarizes the elements and sources of innovation in organizations, shows primary categories associated with them, and offers a selection of references.

\subsection{STRUCTURE OF THE BOOK}

This book has ten chapters grouped in four parts. Part I, Innovations and Organizations, includes the first two chapters. In this first chapter we provided a general overview of innovation studies in business and management, exhibiting the book's approach in presenting and explaining the theory and research on innovations in organizations. Two perspectives of competition-wealth and adaptation-progression, four primary elements of innovation, and four primary sources of organizational innovations were introduced to frame the book's content and approach. These will be used throughout the book to make sense of the fragmented research on organizational innovation, facilitate integrating results of current studies of antecedents and performance consequences of innovation, and propose directions for future investigations to advance theory and evidence-based research on organizational innovation. 
Table 1.1 Elements and sources of innovation

\begin{tabular}{|c|c|c|}
\hline Element & Description & Reference \\
\hline $\begin{array}{l}\text { Type of } \\
\text { innovation }\end{array}$ & $\begin{array}{l}\text { Typologies of innovation group innovations according } \\
\text { to their nature, features, or function in order to reduce } \\
\text { complexity and facilitate determining their antecedents and } \\
\text { consequences. } \\
\text { - Product-process typology: a product innovation is } \\
\text { a new object or service to meet an external user need, and } \\
\text { a process innovation is a new way of making the product } \\
\text { or rendering the service. } \\
\text { - Technical-nontechnical typology: this classification } \\
\text { distinguishes between innovations that are primarily } \\
\text { technology-based (product, process) and those that are not } \\
\text { (management, marketing). }\end{array}$ & $\begin{array}{l}\text { Daft (1978); Cohen and } \\
\text { Klepper (1996); Damanpour } \\
\text { (2010); Ettlie et al. (1984); } \\
\text { Evan (1966); OECD (2005); } \\
\text { Scherer (1983); Storey et al. } \\
\text { (2016); Utterback (1994); } \\
\text { Zaltman et al. (1973) }\end{array}$ \\
\hline $\begin{array}{l}\text { Innovation } \\
\text { radicalness }\end{array}$ & $\begin{array}{l}\text { Radicalness specifies the scale or magnitude of innovation } \\
\text { based on its originality, difference, and/or impact. It is } \\
\text { the extent to which the innovation advances the existing } \\
\text { knowledge, departs from the existing product or practice, } \\
\text { or changes the adopter's behavior or performance. } \\
\text { - Incremental innovation differs or causes minor changes } \\
\text { in organizational internal activities or outputs. } \\
\text { - Radical innovation differs or causes major changes in } \\
\text { organizational internal activities or outputs. }\end{array}$ & $\begin{array}{l}\text { De Brentani (2001); Dewar } \\
\text { and Dutton (1986); Garcia } \\
\text { and Calantone (2002); } \\
\text { Germain (1996); Harvey and } \\
\text { Mills (1971); Knight (1967); } \\
\text { Slater et al. (2014); Van } \\
\text { Lancker et al. (2016) }\end{array}$ \\
\hline $\begin{array}{l}\text { Innovation } \\
\text { process }\end{array}$ & $\begin{array}{l}\text { Process models of innovation conceptualize the sequential } \\
\text { phases or stages through which an innovation passes. They } \\
\text { are simplifications of reality to help understanding the } \\
\text { complex process of generating or adopting innovations in } \\
\text { organizations. } \\
\text { - Generation process depicts how the organization } \\
\text { researches, develops, and commercializes an innovation. } \\
\text { - Adoption process depicts how the organization selects, } \\
\text { adapts, and implements an innovation. }\end{array}$ & $\begin{array}{l}\text { Birkinshaw et al. (2008); } \\
\text { Ettlie and Reza (1992); } \\
\text { Gopalakrishnan and } \\
\text { Damanpour (1994); Marquis } \\
\text { (1969), Pérez-Luño et al. } \\
\text { (2011); Perrini et al. (2010); } \\
\text { Roberts (2007); Saren } \\
\text { (1984) }\end{array}$ \\
\hline
\end{tabular}




\begin{tabular}{|c|c|c|}
\hline Element & Description & Reference \\
\hline $\begin{array}{l}\text { Innovation } \\
\text { openness }\end{array}$ & $\begin{array}{l}\text { Openness represents the locus of innovation. It is the } \\
\text { extent to which an organization involves external players } \\
\text { in the process of generating or adopting innovations. } \\
\text { - Organic innovations pertain to the generation and } \\
\text { adoption of technological and nontechnological } \\
\text { innovations where the focal organization tightly controls } \\
\text { the innovation process. } \\
\text { - Open innovations pertain to the generation and adoption } \\
\text { of technological and nontechnological innovations where } \\
\text { the focal organization involves external players in one or } \\
\text { more stages of the innovation process. }\end{array}$ & $\begin{array}{l}\text { Chesbrough (2003a, } \\
\text { b); Barge-Gil (2010); } \\
\text { Damanpour (2017); Felin } \\
\text { and Zenger (2014); Garriga } \\
\text { et al. (2013); Laursen and } \\
\text { Salter (2014); Lichtenthaler } \\
\text { (2011); West and Bogers } \\
\text { (2014) }\end{array}$ \\
\hline $\begin{array}{l}\text { Sources of } \\
\text { innovation }\end{array}$ & $\begin{array}{l}\text { Sources of innovation are causes or drivers that influence } \\
\text { the creation or application of innovations in organizations. } \\
\text { They are grouped into four dimensions: } \\
\text { - Environmental dimension reflects the characteristics of } \\
\text { entities outside of an organization's boundary that could } \\
\text { affect innovation activities the organization undertakes. } \\
\text { - Organizational dimension represents internal } \\
\text { organizational features such as strategy and structure } \\
\text { whose choices rest within the authority of organizational } \\
\text { decision makers. } \\
\text { - Individual dimensions refer to demographic and personal } \\
\text { characteristics of managers and non-managers that could } \\
\text { facilitate or hinder organizational innovations. } \\
\text { - Innovation attributes are characteristics that signify } \\
\text { differences between individual innovations or pairs of } \\
\text { innovation types. }\end{array}$ & $\begin{array}{l}\text { Baldridge and Burnham, } \\
\text { (1975); Cohen and Levin } \\
\text { (1989); de Vries et al. } \\
\text { (2016); Elenkov et al. } \\
\text { (2005); Frambach and } \\
\text { Schillewaert (2002); } \\
\text { Kimberly and Evanisko } \\
\text { (1981); Kraft and Bausch } \\
\text { (2016); Tornatzky and } \\
\text { Klein, (1982); Vincent et al. } \\
\text { (2018); Yuan and Woodman } \\
\text { (2010) }\end{array}$ \\
\hline
\end{tabular}

Chapter 2 covers concepts and theories of organizational innovation, and contexts within which the empirical studies have been conducted. Innovation overlaps with other concepts, its meaning and purpose varies across disciplinary fields, even the branches of one field, and its understanding is often fashioned to the context of the study. While research in each field is amply justified by the theories of innovation in that field, conceptual and contextual diversity burdens learning across the fields. In the first section, innovation is distinguished from technology, invention, creativity, technological, and organizational change. In the second section, economic-based and behavioral-based theories through which research on organizational innovation is explained and understood are reviewed. In the third section, contextual differences in innovation research are discussed. In particular, the role of organizational types business-public, small-large, manufacturing-service, and start-up-incumbent - is highlighted. 
Part II includes four chapters, where innovation elements are defined and conceptual models to guide research are introduced. Chapter 3 presents prominent typologies of innovation. The classification of innovation into types help reduce the complexity of the construct, enabling the development of evidence-based research and theories. The polar types - technological and nontechnological, outcome and process, internal and external - are presented. Innovation types that overlap markedly are identified to reduce noise; those that are weakly conceptualized or scarcely investigated are recognized; and those for which evidenced-based studies are lacking are noted. Special attention is paid to distinguish service innovation from product innovation, and to promote research on social (responsible, sustainable) innovations. Regarding the large share of services in the economies of many countries and regions, service innovations are under-studied. Research on social innovations is a relatively new area of innovation studies; however, the potential contributions of these innovations to promote social good and impede social harm cannot be overstated.

Chapter 4 details the radicalness of innovation. Innovation radicalness is defined as the extent to which the innovation advances the existing knowledge, departs from existing products, practices, and routines, and changes the focal organization's conduct and outcome. The terminology and typologies of radicalness at the organization and industry level are chronicled, conceptualizations of innovation along the spectrum of radicalness are presented, and multidimensional models of radicalness to guide empirical investigations are proposed.

Chapter 5 classifies innovation process models into generation and adoption processes, suggesting that the two processes differ, and occur either in two organizations or in two units of the same organization. The generation process results in supplying the innovation to the market for adoption; the adoption process results in selecting and acquiring the innovation from the market for implementation and use. The process models of the generation of technological, managerial, service, and social innovations are exemplified. The chapter concludes that sources of innovation generation and adoption may differ, and the distinction between the two processes is essential for accurate estimation of the salient determinants of organizational innovations.

Chapter 6 details innovation openness, considering it as a continuum, and associating it with the process of innovation. The emerging literature on open innovation is reviewed, and openness is defined as the extent to which organizations involve external actors or entities in generating or adopting of technical or nontechnical innovations. Innovation openness is juxtaposed with typologies of innovation to offer conceptual models for future research. Ideas for expanding innovation openness to include involvement of internal actors 
and integrating the concept of open innovation with more established elements of organizational innovation are presented.

Part III, Sources of Innovation in Organizations, presents causes or drivers of innovations in organizations in two chapters. Studies of the factors that influence innovation and help distinguish between innovating and non-innovating organizations constitute the largest body of organizational innovation literature. Chapter 7 identifies external and internal factors that drive innovation in organizations, and conducts a meta-synthesis of empirical findings on the determinant-innovation relationships to convey the current state of research. Innovation antecedents are classified into four groups: environmental, macro-organizational, micro-organizational, and innovation characteristics. Macro-organizational characteristics include strategy, structure, and process antecedents; micro-organizational characteristics include attributes of organizational leaders and leadership styles. It is argued that these characteristics in unison shape organizational capabilities to stimulate innovation. The chapter draws from 21 meta-analytical reviews to compare empirical findings and identify salient external and internal determinants of innovation in organizations.

Chapter 8 conducts a meta-synthesis of theoretical and methodological moderators of the sources identified in Chapter 7 and discusses sources of agreements and disagreements in the empirical studies. Since quantitative integrations of mediation models are scarce, the influence of several primary mediating variables such as organizational learning, culture, knowledge management, and human resource practices are discussed using the original studies. Via a narrative integration of mediating models, a conceptual framework to guide future investigations is suggested. Throughout both Chapters 7 and 8 , summaries of consistent findings are offered to show the current state of empirical research and suggest directions for future research.

The popularity of innovation in organizations rests on the expectation that innovation is a positive driver of organizational performance. Chapters 9 and 10 in Part IV, Performance Consequences of Innovation, review and integrate studies of innovation outcome. Chapter 9 deliberates in which contexts, under what conditions, and to what extent organizational innovativeness affects organizational performance, completing the determinant $\rightarrow$ innovation $\rightarrow$ performance chain of relations. First, three prominent theoretical perspectives of innovation and performance - first mover advantage, performance gap, and institutional - are reviewed. Then a meta-synthesis of the findings from 13 quantitative reviews are conducted to unveil whether performance consequences of innovation in organization is contingent on one or more element of innovation, as well as the study's context. A conceptual model for studying organizational innovation and performance is suggested to assist empirical investigations. 


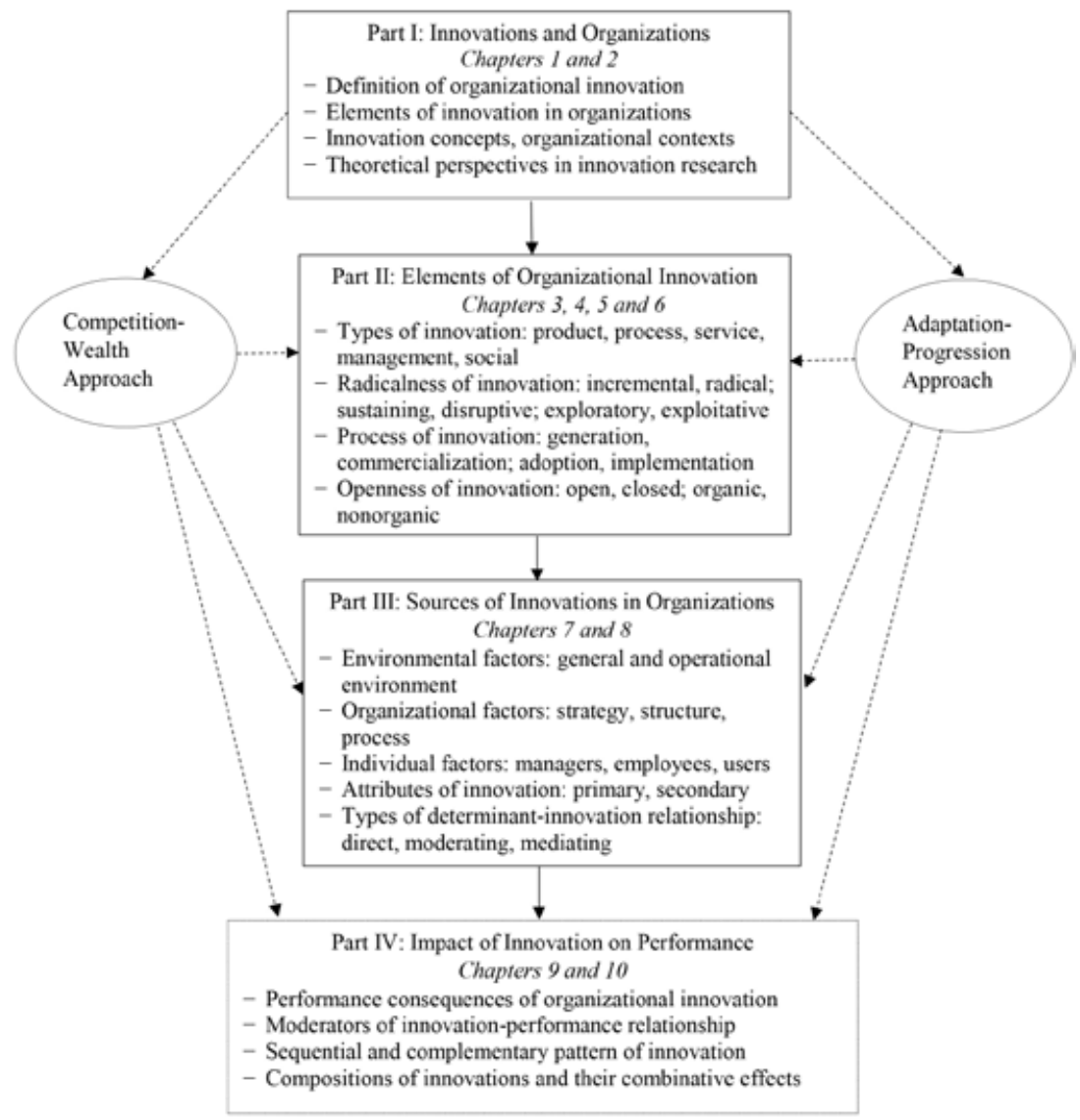

Figure 1.5 Structure of the book

Research on the innovation-performance relationship has mainly examined the effects of single types of innovation, often product innovations. In Chapter 10, we rely on insights from system theory, sociotechnical systems, resource-based view, and dynamic capability to argue that the performance consequences of innovation emanate from the collective generation and adoption of related innovations associated with different functions and operations of the organization. Patterns of the introduction of innovation at the industry-level and firm-level are described, and synchronous or complementary innovations are defined. Empirical studies of 'complementarity-in-use' and 'complementarity-in-performance' are reviewed, and their results are integrated in order to guide new research on complementary innovations 
and their combinative effects on performance. The chapter concludes that, contradictory to the popular perception of the positive effects of discontinuous innovations, organizational competitiveness and effectiveness result from the introduction of complementary innovations and their combinative effect on firm performance. Figure 1.5 shows the flow of the chapters and summarizes the main topics addressed in each.

\section{NOTES}

1. Relying upon the Social Sciences Citation Index (SSCI), one of the collections in Web of Science maintained by Clarivate Analytics which covers more than 3000 journals in social science disciplines, we selected journals in the management discipline in 2019, searched the articles published in these journals from 1960 to 2019 and identified 6172 publications with the word 'innovation' in their titles.

2 The pro-innovation bias is also prevalent in the academic community, resulting in many studies of conditions and circumstances that motivate innovations in organizations, and impact of innovation on organizational performance, but few studies on why and how innovations may fail, and what economic and social repercussion innovation might entail. A dearth of data on the failure of organizational innovation exacerbates this shortcoming.

3. The definition of generation and adoption differs. For generation, innovation is defined as the creation of a new idea pertaining to object or practice and its distributions in the population of adopters (Birkinshaw et al., 2008; Roberts, 1988). For adoption, innovation is defined as the introduction of a system, program, or practice new to an internal unit or the entire organization (Damanpour, 1987; Wolfe, 1994). For details see Chapter 5.

4. It is necessary to note that 'organizational innovation' as viewed here is not synonymous with Schumpeter's fifth type (Damanpour, 2014). Schumpeter's 'new ways of organizing business' refers to organizing at the industry level, like the creation of a monopoly position or the breaking up of a monopoly position (Schumpeter, 1934, p. 66). It relates to Schumpeter's early work where innovation reflects discontinuous change driven by new firms through technology push; that is, new companies that act as agents of change in established industries.

5. The term organizational innovation in OECD (2005) and CIS does not represent organizational innovation as defined in this volume. Rather, it coincides with the term administrative (later managerial and management) innovation as will be explained in Chapter 3.

6. To identify the number of studies that focused on at least one of the four types of innovation, we search the 6172 articles (see endnote 1), coupling the word 'innovation' with the following words as appearing in titles of articles: (1) product/ service innovation, the word 'product' or 'service'; (2) technological innovation, the words 'technical,' 'technological,' 'architectural,' 'product,' or 'process'; (3) management innovation, the words 'administrative,' 'managerial,' or 'management'; (4) and marketing innovation, the word 'marketing'. It is necessary to state that the number of marketing innovations in Figure 1.2 is much lower than it really is because we searched SSCI journals in management only. The true number requires a search of marketing journals as well. 
7. Indeed, a reason for lack of research on nontechnological innovations is that they cannot be protected from imitators because they cannot be patented. While nontechnological innovations may add value, the generating organization may not be able to reap the benefit of its investment on them because of imitation. In this case, inadequacy of 'impact' overshadows 'originality' and 'departure.'

8. It is necessary to say that the distinction between generation and adoption processes do not necessarily correspond with 'supply-pushed' (technology-push) versus 'demand-led' (market-pull). Technology-push and market-pull generally represent rival $\mathrm{R} \& \mathrm{D}$ strategies concerning technology-based commercial innovations.

9. The distinction between generation and adoption posits that innovation can be developed in one organization and applied in another. The emphasis on separating these processes, however, does not suggest that organizations do not develop innovation for own use. In such cases, however, innovation is usually developed in one part or unit of organization ( $R \& D$, product development, design) and is used in another unit (manufacturing, marketing, human resources) (Damanpour, 2017).

10. Not every combination in the models of Figure 1.3 is sufficiently common to justify investigation. Thus far, no empirical study has entertained any two-by-three combination. The majority of current studies have dealt with only one element of innovation, although a small minority has examined combinations of two pairs of innovation (e.g., product-process with incremental-radical). For details see Chapters 3 and 4. 